\title{
A estética da desregulação da violência doméstica em Marina Colasanti
}

Carlos Magno Gomes*

\section{Resumo}

Este artigo apresenta um estudo acerca das regulações de gênero que normatizam a violência doméstica pela análise da obra Contos de amor rasgados (1986), de Marina Colasanti. Partimos do conceito de revisão paródica, de Linda Hutcheon, para identificar a caricatura da masculinidade como uma forma de deslocamento das normas de gênero. De acordo com os estudos acadêmicos de Judith Butler, Henrietta Moore, Lia Zanotta Machado e Rita Laura Segato, apresentamos a violência de gênero e o excesso de masculinidade como práticas de controle moral e físico da mulher. Especificamente, investigamos como são representados os valores morais atrelados à questão da honra e à crise identitária das personagens masculinas.

\section{Palavras-chave}

Violência doméstica. Antropologia de gênero. Literatura contemporânea.

\begin{abstract}
This article presents a study about gender regulations that make domestic violence normative from the analysis of Contos de Amor Rasgados (Torn Love Tales) (1986), by Marina Colasanti. We are working with the concept of parodic revision by Linda Hutcheon to identify the caricature of masculinity as a form of displacement of gender norms. According to academic studies by Judith Butler, Henrietta Moore, Lia Zanotta Machado and Rita Laura Segato, we present the gender violence and the excess of masculinity as practices of moral and physical control over women. Specifically, we investigate how moral values bound to the question of honor and the identity crisis of masculine characters are represented.
\end{abstract}

\section{Keywords}

Domestic Violence. Gender Anthropology. Contemporary Literature.

\footnotetext{
* Carlos Magno Gomes é professor de Teoria Literária vinculado ao PROFLETRAS e ao PPGL da UFS. Doutor em Literatura pela UnB (2004). Pesquisador bolsista CNPq e membro do GT da ANPOLL A mulher na literatura.E-mail: calmag@bol.com.br.
} 


\section{Apresentação}

Os estudos feministas questionam as regulações sociais que estão por trás da violência contra a mulher como as normas simbólicas de imposição da masculinidade, e a estrutura de exploração do corpo feminino como uma extensão do desejo masculino. Em muitos casos, a regulação do corpo feminino é mantida por abusos físicos e privações sociais em sistemas de torturas e de constantes ameaças. No Brasil, a Lei Maria da Penha (2006) e a Lei do Feminicídio (2015) punem os agressores com mais rigor e foram criadas, a partir da luta das mulheres, para conter esses crimes e proteger as vítimas. Todavia, a recorrência dessas agressões indica que devemos ir além da aplicação de penas mais severas e medidas protetoras, pois os valores simbólicos que atravessam esses crimes são construídos coletivamente e extrapolam as fronteiras da legislação em vigor ${ }^{1}$.

No contexto familiar, a recorrência do assédio moral, do cárcere privado e das agressões físicas, que, quase sempre, antecedem o feminicídio, reforçam valores morais que estão centrados em uma contradição social que reconhece a liberdade da mulher ao mesmo tempo em que veicula discursos de domínio do corpo feminino como parte do exercício da masculinidade. Tais práticas são tipificadas como violência doméstica e são reconhecidas pela população brasileira, como comprova a pesquisa do Instituto Patrícia Galvão (BRASIL, 2014) acerca da percepção da sociedade sobre violência e assassinatos de mulheres. Esse levantamento traz diversos dados acerca de como homens e mulheres percebem a dimensão social do feminicídio. Os resultados foram catalogados, no ano anterior, em mais de 100 municípios das cinco regiões brasileiras, envolvendo diversas classes sociais conforme a renda familiar per capita.

Entre as constatações da vulnerabilidade feminina, destacamos que $70 \%$ dos entrevistados acreditam que a mulher está mais sujeita à violência de gênero em casa (BRASIL, 2014, p. 19). Essa percepção denuncia o reconhecimento da violência como uma forma de controle e punição da companheira no espaço familiar. Para $85 \%$ dos participantes dessa pesquisa, "as mulheres que denunciam seus parceiros correm mais risco de sofrer assassinato" (BRASIL, 2014, p. 05). Infelizmente, tais dados dão sinais da

\footnotetext{
${ }^{1}$ Este texto traz os resultados de uma pesquisa de pós-doutorado desenvolvida junto ao Programa de Pós-Graduação em Antropologia Social da UnB (2016-2018), supervisionada pela Profa. Dra. Lia Zanotta Machado, acerca do feminicídio na literatura brasileira, com financiamento do CNPq.
} 
violência doméstica como uma epidemia social.

Tal prática está atrelada às normas sociais simbólicas que primam pela valorização da força e da virilidade masculina como marcas da normatização do corpo do homem. No espaço doméstico, a ideia de posse do corpo da mulher e a agressividade masculina dão o ritmo das agressões que, em muitos casos, provocam lesões fatais que podem chegar ao feminicídio. Retomando dados da pesquisa anterior, identificamos o homicídio feminino como uma das punições mais praticadas por homens obsessivos. Para 92\% dos entrevistados, as mulheres que sofrem violência doméstica com frequência estão sujeitas a serem assassinadas (BRASIL, 2014, p. 35).

Essa percepção acerca da violência contra a mulher reforça que não estamos diante de casos isolados, mas de comportamentos que se repetem diariamente. De acordo com os estudos antropológicos e feministas de Rita Laura Segato (2005, p. 270), os crimes de gênero "não são obra de desvios individuais, doentes mentais ou anomalias sociais, mas de expressões de uma estrutura simbólica profunda que organiza nossos atos e nossas fantasias e confere-lhes inteligibilidade". O reconhecimento dessa estrutura que regula a violência contra a mulher nos convida a identificar as normas dessa perversa forma de punição feminina.

Essa violência também pode ser identificada nas representações estéticas por meio de duas perspectivas: aquelas que repetem a temática sem reflexões críticas; ou aquelas que retomam essas representações com o intuito de questionar e/ou denunciar as formas de controle do corpo feminino. Por exemplo, nas narrativas realistas do século XIX e XX, a violência contra a mulher é descrita como parte da normatização da moral patriarcal, identificada na representação de personagens masculinas ciumentas e possessivas que punem suas esposas, quando desconfiam que são traídas, como representado nos romances Dom Casmurro (1899), de Machado de Assis, e São Bernardo (1934), de Graciliano Ramos. Essas narrativas registram a violência doméstica pelo prisma masculino, segundo o qual a punição é naturalizada para valorizar e respaldar a moral e a masculinidade do agressor.

Em contrapartida, ainda durante o século XX, essa normatização de gênero passou a ser questionada pelos textos de autoria feminina, como em O quinze (1930), de Rachel de Queiroz, com uma protagonista que rompe com um namorado, após se recusar a repetir o "destino de mulher" e ser submissa às ordens do marido; e Perto do coração selvagem (1944), de Clarice 
Lispector, que traz uma jovem em formação que rompe com os papéis tradicionais de menina, moça e mulher obediente para viver sua liberdade.

Além desses romances, destacamos alguns contos contemporâneos que deslocam o privilégio masculino para detalhar o quanto a mulher é vítima de uma estrutura perversa de controle e punição, como em "Venha ver do pôr de sol" (1970), de Lygia Fagundes Telles, e "A língua do P" (1974), de Clarice Lispector. Nesses contos, o desnudamento das engrenagens de violência fica mais explícito, denudando "paradigmas culturais" que estão por trás da violência contra a mulher (GOMES, 2014).

Diante das especificidades e contradições que dão sustentação a essa violência, identificadas tanto na sociedade como nas narrativas da literatura brasileira, este artigo abre o debate sobre as regulações e normas que dão sustentação à violência doméstica pela interpretação dos valores morais masculinos, descritos na obra Contos de amor rasgados (1986), de Marina Colasanti. Esse livro é composto por minicontos que exploram temas como paixão, amor, infidelidade, ciúme, entre outros, próprios do cotidiano de um casamento, descrevendo também a violência sofrida pela mulher nesse espaço, com destaque para o cárcere privado e para o feminicídio. Especificamente, investigamos os valores sociais da "questão da honra" como justificativa para o assassinato da esposa no casamento. Para isso, analisaremos o assédio psicológico e a traição imaginária, no conto "Para que ninguém a quisesse", e a crise de masculinidade em "Com a honra no varal".

Esses minicontos desmascaram a estrutura social que condena as mulheres a punições e ao feminicídio pela crise de masculinidade e subjetividade de um marido traído. Para nossa análise, recorremos a uma base teórica interdisciplinar, respaldada pelos estudos antropológicos. Partiremos das contribuições feministas para a ampliação dos sentidos da violência contra a mulher, levando em conta que essa violência é parte de outra, estrutural, hegemônica e reproduzida pelas normas sociais. Dentro dos estudos acerca da normatização das regras de gênero, debateremos sobre as desregulações, propostas de Judith Butler (2014), a obsolescência da honra familiar, articulada por Lia Zanotta Machado (2014), e a crise de masculinidade, identificada por Henrietta Moore (2000). 


\section{A estrutura da violência de gênero}

A agressão contra a mulher é parte de uma complexa rede de valores que dão sustentação aos diferentes tipos de violência doméstica e nos convida a uma reflexão sobre as causas de sua recorrência, pois nos interessa analisar se se trata da manutenção de uma norma simbólica ou de um desvio de comportamento individual. Em outras palavras, está em jogo analisar se essa violência é representada como ruptura ou como uma continuidade nos textos de Marina Colasanti. Tais questionamentos fazem parte de uma estratégia de revisão dos valores sociais que fundamentam a violência de gênero. Em tal empreitada, precisamos entender como os mecanismos morais são incorporados às práticas sociais.

Por fazer parte dessas práticas, a violência contra a mulher precisa ser analisada pelo duplo movimento que a impulsiona: as instâncias das regulações e as operações de poder. Tanto seu campo simbólico quanto a maneira como ela se repete socialmente são relevantes para uma visão mais ampla dos valores que dão sustentação a esse ato. Judith Butler propõe um deslocamento do imaginário simbólico para as normas culturais generificadas da imposição do poder masculino, visto que a norma é um produto cultural que se mantém pela citação, isto é, "somente pela virtude de seu poder repetido de conferir realidade, é que a norma é constituída como uma norma" (BUTLER, 2014, p. 267).

Diante das tensões entre a "legitimação dos valores iguais de gênero" e os "valores de longa duração dos códigos relacionais da honra", destacamos a questão da honra como um contrato simbólico do casamento que reforça as desigualdades de gênero (MACHADO, 2014, p. 111). A crise de masculinidade faz parte desse repertório e é antecedida por uma crise da representação, que tem como pano de fundo "conflitos e estratégias sociais ligadas" aos modos de representação (MOORE, 2000, p. 41). Tanto a honra familiar como a crise de masculinidade fazem parte desses conflitos sociais que precisam ser mais bem debatidos.

No Brasil, a violência contra a mulher vem de longa data e é parte da cultura patriarcal herdada de uma sociedade excludente e extremamente controladora e disciplinadora. Logo, como parte de normas coletivas, essa violência "não é exterior ao seu campo de aplicação", pois "é produzida na produção desse campo" (BUTLER, 2014, p. 267). Ao reconhecermos a violência como uma norma, realizada dentro do campo de regulação de gênero, pretendemos fazer uma reflexão sobre os subsídios simbólicos que 
insistem em aprisionar a mulher a valores masculinos.

Portanto, estamos diante de um debate que perpassa a questão da violência como parte do imaginário de controle patriarcal para se reestruturar por meio de reflexões acerca dos conceitos de sexo/gênero e poder que confirmam que há "relações desiguais de gênero", quando identificamos o elogio masculino da força e da agressividade (MACHADO, 2014, p. 124). Para desnudar as sutilezas com que a violência é regulada, tentamos fugir de categorias homogeneizantes, quando pensamos em causas e contextos e quando buscamos compreender as relações de poder, pois os valores relacionados ao patriarcado também estão se adaptando aos novos contextos. Segundo Wânia Pasinato, o patriarcado "sofreu transformações para garantir sua sobrevivência num mundo em que os papéis sociais de gênero estão mudando em velocidade vertiginosa" (PASINATO, 2011, p. 237).

Outro aspecto usado culturalmente para invisibilizar essa violência está relacionado à relativização do assédio sexual como exercício da masculinidade. Minimizar a responsabilidade do agressor faz parte do repertório popular. Tal comportamento pode ser identificado nas interpretações da violência sexual, nas quais a mulher ainda é vista como "culpada", quando sorriu, ou usou uma roupa mais sensual, "dando oportunidade" ao violador de agir. Tal forma de relativização se enquadra como parte das tênues fronteiras entre o assédio e a fantasia masculina, que estão relacionadas aos processos de representação "tanto individual como social" (MOORE, 2000, p. 43).

Além disso, em volta dessa estreita fronteira entre violência e fantasia, repete-se um discurso de medo das mulheres que passa pela valorização do poder masculino no qual "o temor e medo das mulheres, ou o sentimento de culpa das mulheres foram construídos reciprocamente pela legitimação do poder de gênero instaurado legalmente de controle e castigo dos homens, com a recíproca culpabilização das mulheres" (MACHADO, 2014, p. 108). Portanto, a violência de gênero é parte de um campo de luta em que velhos padrões são impostos "de maneira transversal", nos quais o corpo feminino é mantido aprisionado ao desejo do homem (PASINATO, 2011, p. 239).

Questionando essa regulação de gênero, a ficção de Marina Colasanti nos proporciona uma densa reflexão acerca das normas que dão sustentação, especificamente, à violência doméstica. Sua literatura é construída por um modelo paródico de revisão dos papéis tradicionais que brincam com valores morais e sociais. Tal particularidade de revisar 
e deslocar o imaginário masculino opressor e a submissão feminina revela uma "literatura pós-moderna", atravessada por "questões ideológicas e políticas" por priorizar representações caricatas da masculinidade tradicional. Essa literatura, em que feminismo e desregulação de gênero se misturam, faz parte das estratégias estéticas dos textos pós-modernos, conforme nos ensina Linda Hutcheon (1993, p. 05). Na continuidade deste artigo, identificamos as particularidades da estética de desregulação de gênero, de Marina Colasanti.

\section{As regras da violência doméstica}

A literatura de Marina Colasanti é marcada por um olhar feminista que desloca valores patriarcais e verdades hegemônicas acerca das relações matrimoniais. Seu universo familiar é um espaço de descentramento e de questionamento das identidades femininas submissas. Seus clássicos infantis da coletânea Doze reis e a moça no labirinto do vento (1978) trazem sátiras do imaginário dos contos de fadas com propostas de revisão da história da mulher. Essas narrativas descrevem protagonistas donas de suas histórias, que procuram seus parceiros e se afastam deles quando se sentem oprimidas. Elas não aceitam o destino de viver à sombra de um príncipe, pois rompem com as regulações próprias do gênero feminino: obediente, submissa e esposa.

Nessas representações literárias, que revisam o imaginário dos contos de fadas, Marina Colasanti desregula as normas de gênero, a partir do modelo paródico de narrar, pois retoma representações femininas homogêneas para deslocá-las para espaços de liberdade. Esse modelo literário é retomado, de forma particular, em Contos de amor rasgados, pois são privilegiadas as descrições irônicas de homens condicionados a repetir apenas as normas do controle e de punição. Essas personagens masculinas, ridicularizadas por atitudes patéticas, são expostas como parte de uma estrutura social, mas com particularidades subjetivas que expõem a estética de desregulação de gênero.

Essa coletânea de minicontos pode ser vista como uma revisão feminista da violência doméstica, uma vez que traz homens vazios e sem rumo após o ato de violência. Historicamente, esses contos antecipam o debate sobre os direitos da mulher, que foram reconhecidos pela Constituição Federal de 1988, mas só ganharam espaço na legislação brasileira após a criação das Leis Maria da Penha (2006) e do Feminicídio (2015), que são exemplos de 
lutas e conquistas feministas.

Além disso, esse livro tem a proeza de questionar o imaginário da honra masculina a partir da representação da crise de identidade de homens sensíveis que se veem desnudados diante de seus atos de punição. Ao deslocar a lógica simbólica do criminoso, Marina Colasanti abre o espaço literário para um debate mais amplo acerca dos valores masculinos, sem cair nos clichês. Sua estética traz uma reflexão acerca da contradição do casamento, calcado em valores obsoletos, como a honra, em oposição ao processo civilizatório que ampliou o "debate em torno da desigualdade social entre os sexos", pois não é o marido, "enquanto indivíduo", que concede a liberdade a uma mulher. "Ela se fundamenta na estrutura da própria sociedade" (ELIAS, 1994, 184).

Partindo dessa abordagem, exploraremos as particularidades do texto literário pós-moderno para argumentar como a violência doméstica é regulada por regras sociais que visam ao controle da sexualidade feminina. Os contos da coletânea Contos de amor rasgados trazem personagens sem nomes, marcados pelos papéis de gênero engendrados na cultura patriarcal, centrada nas regulações de gênero que primam pela moral masculina. Partimos para a identificação do modelo paródico na análise da traição imaginária no miniconto "Para que ninguém a quisesse", que retrata a proporcionalidade do aumento da violência por meio da vigilância do corpo da esposa.

O conto se inicia narrando o cotidiano de um casal, expondo o ciúme doentio do marido, que vai aniquilando a autoestima da mulher e o prazer entre eles. O marido impõe um severo controle ao corpo da esposa por medo de ter sua honra manchada socialmente. O convívio com amigos e a participação em festas ficam para trás, quando ele se sente ameaçado pela beleza da mulher, dando início à tortura psicológica. Especificamente, esse tipo de violência é consequência de uma "ameaça imaginária", que faz parte da regulação de gênero, visto que "esposas são muitas vezes espancadas por infidelidades imaginárias, o que torna a violência e a ameaça de violência mais eficaz como meio de controle social" (MOORE, 2000, p. 39).

A ameaça imaginária produz duras normas de controle do corpo da mulher e do confinamento em cárcere privado. No conto, a imposição do controle é vertical, não há espaço para a voz da mulher. Temos acesso ao discurso disciplinador do marido: "mandou que descesse a bainha dos vestidos e parasse de se pintar" (COLASANTI, 2010, p. 111). Esse controle é um dos primeiros passos do homem em crise com seus valores pessoais e 
sociais, relevando contradições de diferentes discursos, coexistentes em um mesmo espaço (MOORE, 2000, p. 27).

No segundo momento, o marido passa a controlar o comportamento social da esposa, visto que a primeira imposição não foi suficiente para reaver sua confiança. Ele passa a impedir que ela explore sua silhueta, exigindo que "eliminasse os decotes, jogasse fora os sapatos de saltos altos" (COLASANTI, 2010, p. 111). Nesse caso, temos um narrador que não dá voz à mulher, mas ironiza a postura masculina de generificar o corpo feminino apenas como extensão dos seus medos e receios. O ciúme doentio vai aniquilando, aos poucos, a autoestima da mulher e o prazer entre eles.

Sem liberdade, sem reconhecimento das regras básicas para uma boa convivência e sem o respeito às normas sociais, o casamento fica vulnerável, pois o "autocontrole" deixa de ser praticado por esse marido, que não respeita hábitos internalizados pela civilização para praticar normas obsoletas de conduta social (ELIAS, 1994, 106). Em um relacionamento com desconfianças, a falta de civilidade transforma a ausência de autocontrole em imposições sem limites. Tal incapacidade é produtora de violência e está relacionada à "administração que outras pessoas fazem de si mesmas enquanto indivíduos marcados por gênero" (MOORE, 2000, p. 39).

Ao construir um homem tão obcecado pelo controle do corpo da mulher, Colasanti reforça que o descontrole masculino nasce do contrato simbólico de que o casamento dá direito de posse do corpo feminino. Diante da insegurança e do ciúme, o desespero do marido se torna evidente, quando resolve amputar a beleza da esposa: "pegou a tesoura e tosquiou-lhe os longos cabelos" (COLASANTI, 2010, p. 111). Essa ação desnuda a violência descomedida do assédio psicológico masculino. Nesse caso, vai além do assédio, pois se trata de tortura.

Ao descrever um homem em crise, desconfiado e em vigilância de uma traição imaginável, essa narrativa abre uma reflexão acerca do controle imposto por maridos ciumentos. Em seus estudos sobre a representação do corpo feminino na literatura brasileira, Elódia Xavier reconhece que a autoria feminina, nas últimas décadas do século XX, passa a questionar o "corpo disciplinado", quando desloca esteticamente "esquemas predeterminados, e repressores" (2007, p. 59).

No conto de Colasanti, esse deslocamento acontece quando a esposa não corresponde à imposição do marido. Se, antes, havia uma vida social, se ela podia acompanhá-lo em encontros com amigos, aos poucos esse comportamento passa a ser visto como perigoso para o marido inseguro. 
Com essa visão, esse conto questiona a violência própria do padrão patriarcal que só aceita mulheres submissas ao desejo exclusivo do marido. Tal exclusividade é excessiva e doentia, mas aceita socialmente quando se trata de relações familiares.

Com o ato final de cortar os cabelos da esposa, eliminando a última marca feminina desta, o marido também lhe corta a possibilidade de vida social. Depois de aprisioná-la aos seus ciúmes doentios, a esposa entra em depressão e passa a viver em silêncio, confundindo-se com as sombras da casa: "E continuou andando pela casa de vestido de chita, enquanto a rosa desbotava sobre a cômoda" (COLASANTI, 2010, p. 112). Com isso, a personagem feminina se opõe a seguir as normas do marido, pois, mesmo sem romper de forma definitiva, ela opta por manter sua construção de feminino e se nega a ser essa mulher controlada.

Além do questionamento do corpo disciplinado, esse conto retoma o debate acerca do espaço do lar no imaginário da mulher. Como parte da estrutura opressora, a casa, representada nesse conto, deixa de ser uma "casa protetora", para ser usada como uma "casa jaula", quando passa a ser o berço da clausura, imposta pelo marido (XAVIER, 2012, p. 41).

Com essas marcas estéticas de denúncia da opressão do corpo da mulher, essa narrativa questiona a regulação de gênero e expõe as contradições desse processo, pois há dois momentos - um de liberdade da mulher e outro de controle e punição. Essa mudança de comportamento é justificada pela falta de segurança que o marido passa a ter, registrando outras posições identitárias que ameaçam o casamento, uma vez que "os indivíduos constituem seu sentido de si mesmos - suas autorrepresentações como sujeitos - por referência a várias posições de sujeito frequentemente contraditórias entre si e não a uma posição singular de sujeito" (MOORE, 2000, p. 23). Tais contradições estão presentes na construção de uma masculinidade opressora e de uma feminilidade resistente.

Esteticamente, o modelo paródico pode ser identificado nos excessos de controle e de vigilância masculinos que beiram à loucura. Tal opção estética pode ser vista "como estratégia de denúncia", pois traz a paródia como uma forma estética de deslocar as posições tradicionais de gênero e "brinca com a justificativa da questão da honra como motivo do feminicídio" (GOMES, 2015, p. 210).

Tais comportamentos são descritos proporcionalmente ao aumento do ciúme e à diminuição da confiança na esposa. Como visto, a casa vai se transformando em uma prisão à medida que a insegurança masculina 
aumenta. Com o cárcere privado, resta à mulher o silenciamento para não perder referência ao seu corpo sensual e exuberante. Portanto, o tom irônico da narrativa denuncia a tentativa de naturalização do corpo da mulher como uma extensão da masculinidade. Isso é frustrado pela resistência da esposa que prefere o silêncio e não interage com aquele tipo de regulação.

No plano ideológico, o modelo paródico de Colasanti desloca as regras de lugar e aponta a frustração masculina como consequência para a violência doméstica. Esse tipo de representação reforça o debate acerca da criminalização da violência doméstica por se tratar de crimes do espaço privado e íntimo dos casais. Para Lia Zanotta Machado, a desqualificação desse crime, como de "bagatela" ou de esfera íntima, reafirma a fronteira da casa como um "espaço de poder desigual e de violência" (MACHADO, 2014, p. 124). Ao denunciar o território da casa como um espaço de tortura, o modelo literário abre debate acerca das sutilezas desse crime e da importância de rejeitarmos todas as formas de assédio moral e psicológico nas relações matrimoniais.

Na sequência, demonstraremos como o modelo literário de Colasanti vai além do deslocamento do excesso de masculinidade e da representação da "traição imaginável" para questionar os valores morais por trás do feminicídio.

\section{A punição como regulação moral}

O modelo paródico de Colasanti é retomado nas cenas que descrevem o feminicídio em Contos de amor rasgados. Esse crime é ironicamente questionado por ser descrito como parte de regulação de gênero que visa punir o desrespeito à "ordem do pai" (PASINATO, 2011, p. 230). As cenas dessa violência estão presentes em "Com a honra no varal", que desnuda normas simbólicas e sociais em torno da honra masculina e da fidelidade feminina, pois expõe as contradições do sujeito masculino em crise com valores próprios da honra familiar (MACHADO, 2014, p. 107).

Nesse texto, temos uma mulher infiel, aprisionada e assediada até a hora da morte, dando destaque para a tortura psicológica. Esse modelo literário abre o debate sobre a normatização do feminicídio como uma regulação, visto que a estrutura de gênero é mais uma vez questionada pelo olhar paródico de Colasanti, que descreve cenas mecânicas de um homem que tenta se vingar da esposa infiel, mas que é surpreendido por valores civilizatórios antes de concluir seu crime. 
Desde o título, "Com a honra no varal", destaca a questão da honra masculina como norte dos valores matrimoniais. No intuito de punir a esposa, ele a mantém em cárcere privado com a ameaça de matá-la, pois passa a planejar a morte dela. O crime premeditado explicita a vingança como o único código de honra possível. Conforme denota o título, a roupa suja e a honra masculina devem ser limpas e expostas socialmente. Nesse caso específico, em volta da honra família, há cobranças relacionadas "à honestidade, isto é, fidelidade ou virgindade das mulheres e que produzia, como contraparte, a submissão e a vergonha das e nas mulheres" (MACHADO, 2014, p. 107).

Ao descrever a esposa encarcerada, esse conto retrata uma estrutura de gênero que destina os sombrios territórios do sacrifício feminino como parte dos contratos sociais. No universo ficcional, a representação do feminicídio está atrelada à regulação do controle do corpo da mulher. A metáfora da necessidade de lavar a roupa reforça a obrigatoriedade de limpar a honra do marido traído. Essa restauração se dá por meio do prazer que ele passa a ter, ao executar um crime premeditado: "preparando-se para abrir o nicho na parede, não tinha dúvida: a esposa adúltera seria emparedada viva" (COLASANTI, 2010, p. 185).

Essa narrativa revela um marido que planeja os mínimos detalhes daquela execução. Ele se prepara para enterrar, viva, sua companheira, a mulher está "trancada no banheiro" e "aguardava seu destino", enquanto isso ele "esmerava-se no acerto justiceiro" (COLASANTI, 2010, p. 185). No contexto familiar, não cabe à mulher o papel de ser infiel. A regulação de gênero patriarcal expurga esse comportamento e prega a punição como um ato simbólico de justiça moral.

Tal representação retoma a discussão das posições masculinas hegemônicas que reservam à mulher o controle pela cultura "da honra familiar e da honra masculina", pregando comportamentos de fidelidade ou virgindade das mulheres, que reforçam moralmente, "como contraparte, a submissão e a vergonha das e nas mulheres" (MACHADO, 2014, p. 107). Além disso, o conto ironiza a satisfação do marido, que tenta limpar sua honra com o castigo fatal, demonstrando alívio ao saber que a mulher será punida: "Ele antegoza o prazer que virá nos dias futuros" (COLASANTI, 2010, p.185).

Nesses casos, não só os valores pessoais estão em jogo, mas há um padrão cultural a ser respeitado: a valorização da honra. O modelo paródico de Colasanti expõe um sujeito masculino que executa um assassinato 
a partir da ideia de limpeza e de pôr ordem moral na família. Ao jogar com esses valores, o texto literário expõe uma crise entre valores pessoais e coletivos. Tal crise é "resultado do conflito entre estratégias sociais que estão intimamente ligadas a esses modos de representação" (MOORE, 2000, p. 41). A traição é vergonhosa para um homem, por isso a vingança é explorada como alívio pessoal de justiça.

Todavia, no modelo literário de Colasanti, esse alívio é colocado de sobreaviso, pois o agressor hesita em matar sua esposa quando pensa na futura desorganização da casa. Quando o homem vingativo deixa de pensar no sacrifício, ele passa a perceber o quanto a mulher é importante para a estrutura organizacional da casa desarrumada, pois ninguém "pôs a mesa", "nenhum almoço o espera" e descobre, "junto à cama descomposta, ninho de sujos panos embolados, que ninguém troca ou lava, onde ninguém, além dele, se deita" (COLASANTI, 2010, p.184).

Com esse quadro de dependência da mulher, de forma humorada, o conto retoma a ideia de punição e passa a explorar a possibilidade do cárcere, já que reconhece que pode deixar a mulher presa na parede, mas com a possibilidade de saída, trocando os tijolos que iam enterrá-la por "fechar a abertura apenas com uma porta" (COLASANTI, 2010, p.184). Com essa reviravolta na mente do criminoso, o modelo literário volta a deslocar os valores de lugar e expõe, de forma cômica, como a vingança é patética. Ao brincar com um sujeito masculino em crise com sua agressividade, esse conto reforça sua postura feminista de questionamento da brutalidade masculina, responsável pela "maior parte dos homicídios de mulheres" que são cometidos em espaços domésticos "por seus parceiros íntimos ou conhecidos" (PASINATO, 2011, p. 242).

Com a desistência do assassinato por questões práticas da vida doméstica, "Com a honra no varal", no plano estético, expõe o riso como uma marca paródica, que ecoa como uma grande piada desse tipo de regulamentação. Tal contraste entre o crime planejado e a desistência por uma questão prática reforça o quanto a violência contra a mulher é um código de defesa de valores ancestrais ultrapassados. Isso acontece porque a honra tornase obsoleta diante das necessidades básicas dos sujeitos civilizados, visto que "o processo civilizador, a despeito da transformação e aumento das limitações que impõe às emoções, é acompanhado permanentemente por tipos de libertação dos mais diversos" (ELIAS, 1994, p. 184).

Para Rita Segato, esse tipo de violência reforça os valores morais de uma comunidade, já que o corpo feminino, sacrificado por um homem 
desonrado, poderá ser mais facilmente "naturalizado pela comunidade" (SEGATO, 2005, p. 278). Por esse prisma, o conto revisa o sistema punitivo, compartilhado coletivamente. O exagero da cena tenta sintetizar, de forma satírica, o quanto a estrutura de gênero é cega e fascista ao propor o sacrifício da mulher adúltera. Com essa visão, o texto literário parodia o feminicídio por defesa da honra, opondo-se a um padrão cultural de controle e posse do corpo da mulher. Esse questionamento é condizente com as obras pósmodernas de autoria feminina que primam pela revisão de valores morais mantidos para beneficiar o sujeito masculino (HUTCHEON, 1993, p. 09).

$\mathrm{Na}$ representação literária, destacamos que está em jogo o fato de a personagem masculina ser traída pela necessidade de ter uma mulher para executar as tarefas domésticas. Esse jogo que o conto propõe com um marido indeciso é uma estratégia estética de reflexão acerca dos conflitos sociais entre civilidade e feminicídio. Infelizmente, na contemporaneidade, nos casos de violência doméstica, tal brutalidade não está restrita à ficção de autoria feminina e muitos homens estão deixando de lado as conquistas do processo civilizador para resgatar códigos obsoletos de honra. Isso é evidente para $56 \%$ dos/as brasileiros/as, entrevistados/as pelo Instituto Patrícia Galvão, ao afirmarem conhecer homens que cometeram violência contra uma companheira ou ex-companheira (BRASIL, 2014, p. 56).

Como uma estética da desregulação da violência, esse modelo paródico traz a visão do quanto a violência de gênero é praticada como parte de contratos imaginários, que rejeitam o processo civilizatório. Ela é cometida por maridos em crise com sua honra e pelos valores morais obsoletos para a legislação brasileira. No conto, a mulher é punida por um marido possessivo e ciumento, que explora a ameaça de assassinato como uma força de punição e vingança. Todavia, a fragilidade desse sujeito, traído por questões de civilidade, expõe a mecanização da honra como uma forma de punição. Ao construir personagens masculinas que raciocinam, Colasanti desnuda a barbárie da violência doméstica, ironizando a obsolescência da honra que motiva o ato mecânico do feminicídio.

\section{Considerações finais}

Ao identificarmos, no texto literário de Colasanti, o modelo paródico de revisão da violência de gênero, constatamos o deslocamento de valores morais, pautados pela questão da honra masculina, em confronto direto com questões civilizatórias. Em comum, essas narrativas explicitam o 
fascismo das regulações de gênero por meio de atos e normas que castigam e culpam as mulheres que estão fora dos padrões familiares conservadores. Suas personagens masculinas são exibidas com dúvidas acerca de normas próprias do processo civilizatório, mesmo depois de cometer crimes contra suas esposas. Nesse processo representacional, a crise de masculinidade está articulada por uma "crise identitária", exposta pela negação da masculinidade opressora (MOORE, 2000, p. 43).

Tal modelo estético desloca a postura punitiva dos agressores para posições subjetivas que expõem os contratos simbólicos por trás da violência de gênero. Em "Para que ninguém a quisesse", a traição imaginária ganha uma versão trágica de uma mulher que vai se transformando em um zumbi à medida que o controle aumenta. Essa estética da desregulação é reforçada pela caricatura do marido obsessivo. A imagem deformada desse homem agressor é uma forma de revisão da regulação do feminino, pois expõe o "excesso" dos processos normativos de gênero (BUTLER, 2014, p. 272).

Quando narra o feminicídio em "Com a honra no varal", Colasanti vai adiante e desloca o assassino para uma crise de valores educacionais. A personagem masculina desse conto entra em crise com os valores civilizatórios. Ele desiste de assassinar a esposa para manter sua casa organizada e ficar livre das preocupações domésticas. Tal opção cômica ridiculariza a questão de honra como um dos princípios reguladores da violência doméstica, expondo o quanto ela é obsoleta diante de valores sociais mais amplos.

Nos dois contos analisados, o texto literário ironiza e contesta práticas sociais, pois, por meio da paródia, se opõe a discursos institucionais que "produzem a alta tolerância em relação à violência contra as mulheres" (MACHADO, 2014, p. 124). Essa tolerância é um desafio a ser superado pela sociedade brasileira, assombrada por tantos casos de feminicídios nos últimos anos. Um dos caminhos é o aumento de penas para os crimes domésticos, conforme constata a pesquisa do Instituto Patrícia Galvão, quando identifica que $85 \%$ da população brasileira acreditam que os agressores/assassinos de mulheres não têm penas condizentes com seus crimes (BRASIL, 2014, p. 50).

Como reflexão final, reconhecemos o modelo literário de revisão de Colasanti como uma tradução feminista, pois se trata de uma estética pós-moderna que tanto desregula as questões de gênero como apresenta uma performance ideológica de resistência. Essa estética desmascara a normatização de gênero para expor os meandros das práticas sociais 
opressoras e relativizadas nos espaços domésticos. Tal tessitura literária é consolidada pelo ritmo paródico de sua narrativa que desloca o fixo e o hegemônico por meio do irônico e o do caricato.

\section{Referências}

BRASIL.

(2014). Pesquisa sobre a Percepção da sociedade sobre violência e assassinato de mulheres. São Paulo: Data Popular e Instituto Patrícia Galvão.

BUTLER, Judith.

(2014). Desregulando gênero. Cadernos Pagu, vol. 42, p. 249-274, Campinas.

COLASANTI, Marina.

(2010). Contos de amor rasgados. 3. ed. Rio de Janeiro: Record.

ELIAS, Norbert.

(1994). O processo civilizador. 2. ed. Rio de Janeiro: Jorge Zahar Ed.

GOMES, Carlos Magno.

(2014). 0 femicídio na ficção de autoria feminina brasileira. Estudos Feministas, v. 22, n. 3, p. 781-794, Florianópolis.

GOMES, Carlos Magno.

(2015). “Ecos sociais do homicídio de mulheres na narrativa contemporânea". In: KAMITA, Rosana; FONTES, Luísa (Orgs.). Mulher $e$ literatura: vozes consequentes. Florianópolis: Mulheres, p. 197-214.

HUTCHEON, Linda.

(1993). La política de la parodia postmoderna. Traducción del inglés por Desiderio Navarro. Revista Criterios. La Habana, edición especial, p. 187-203. Disponivel em: http://www. criterios.es/pdf/hutcheonpolitica.pdf. Acesso em 15 de mai. de 2017.
MACHAD0, Lia Zanotta.

(2014). “0 medo urbano e a violência de gênero". In: MACHAD0, Lia Zanotta; BORGES, Antonádia Monteiro; MOURA, Cristina Patriota de.(Orgs.). A cidade e o medo. Brasília: Verbena/Francis, p. 103-125.

M00RE, Henrietta.

(2000). Fantasias de poder e fantasias de identidade: gênero, raça e violência. Cadernos Pagu, v. 14, p. 13-44, Campinas.

PASINATO, Wânia.

(2011). Feminicídios e as mortes de mulheres no Brasil. Cadernos Pagu, v. 37, p. 219-246, Campinas.

SEGATO. Rita Laura.

(2005). Território, soberania e crimes de segundo Estado: a escritura nos corpos das mulheres de Ciudad Juarez. Estudos Feministas, v. 13, n. 2, p. 265-285, Florianópolis.

XAVIER, Elódia.

(2007). Que corpo é esse? 0 corpo no imaginário feminino. Santa Catarina: Mulheres.

XAVIER, Elódia.

(2012.) A casa na ficção de autoria feminina. Florianópolis: Mulheres.

\section{Recebido em}

julho de 2017

\section{Aprovado em}

fevereiro de 2018 